\title{
Resenha
}

\section{Temas avançados de Direito da Saúde: tutelas jurídicas da saúde}

Review

Advanced health law themes: legal health tutelage

Reseña

Temas de derecho de salud avanzado: tutela legal de salud

Edith Maria Barbosa Ramos ${ }^{1}$

Laísse Lima Silva Costa ${ }^{2}$

Natalie Maria de Oliveira de Almeida ${ }^{3}$

A obra Temas Avançados de Direito da Saúde: tutelas jurídicas da saúde, organizada pelo professor e pesquisador Marcelo Lamy, é constituída de seis partes: Direto da Saúde e Tutela Penal; Direito da Saúde e Tutela Civil; Direito da Saúde e Tutela Trabalhista; Direito da Saúde e Meio Ambiente; Direito da Saúde e Políticas; e Direito da Saúde e o SUS, com um total de 20 artigos. Os artigos são resultado final ou parcial de pesquisas realizadas pelos docentes discentes e egressos do Programa de Pós-Graduação Direito da Saúde: Dimensões Individuais e Coletivas, da Universidade Santa Cecília (Unisanta).

A primeira parte aborda o direito da saúde e tutela penal e encontra-se composta por três artigos. No primeiro, nomeado Mandados de criminalização e proteção à saúde (1), Fontes analisa de que maneira e em que medida o bem jurídico saúde, considerado interesse fundamental, humano e social, se revela um interesse que possui dignidade, merecimento e necessidade de tutela penal.

No segundo, Mandado de criminalização do tráfico ilícito de entorpecentes: o caso das drogas sintéticas (2), Gouveia e Souza pretendem indicar as dificuldades enfrentadas pela força policial em cumprir o mandado de criminalização referente ao crime de tráfico ilícito de entorpecentes, previsto no artigo $5^{\circ}$, inciso XLIII, 2aㅡ parte, e no artigo 243 , parágrafo único, da Constituição Federal, no caso específico das drogas sintéticas, bem como buscar soluções para essas questões.

\footnotetext{
${ }^{1}$ Pós-doutora em Direito Sanitário, Fundação Oswaldo Cruz, Brasília, Brasília, DF, Brasil; professora, Faculdade de Direito, Universidade Federal do Maranhão, São Luís, Maranhão, Brasil. https://orcid.org/0000-0001-6064-1879. E-mail: edithramosadv@yahoo.com.br

${ }^{2}$ Mestranda em Direito e Instituições do Sistema de Justiça, Universidade Federal do Maranhão, São Luís, Maranhão, Brasil. https://orcid.org/0000-0001-6181-9405. E-mail: laisse_Is@hotmail.com

${ }^{3}$ Mestranda em Direito e Instituições do Sistema de Justiça, Universidade Federal do Maranhão, São Luís, Maranhão, Brasil. https://orcid.org/0000-0002-1731-460X. E-mail: natalie_oam@hotmail.com
} 
No terceiro artigo, Saúde e doenças no cárcere: fatores de produção e negligência estatal (3), Felício e Lamy asseveram a existência de um verdadeiro abismo entre o direito à saúde formalmente admitido e a sua concretização no âmbito da saúde prisional. Elencam uma série de fatores de produção de doenças, que agravariam o quadro nacional de enfermidades e gerariam um contexto prisional gravemente infecto, refletindo a negligência estatal, já que não haveria um combate, de forma estrutural, aos problemas sanitários do cárcere.

A segunda parte da obra trata-se do direito da saúde e tutela civil, e está dividida em quatro artigos. No primeiro, intitulado Deficiências da perícia nas alienações parentais (4), assevera Bastos que, em razão de uma quantidade expressiva e crescente de ações que envolvem a alienação parental, o Poder Judiciário estaria sobrecarregado, atuando de maneira insuficiente, diante da escassez de profissionais para a realização de perícias, imprescindíveis para subsidiar as decisões judiciais nessas questões.

O segundo artigo, O Ministério Público Federal e a tutela do direito à saúde mental (5) de autoria de Silva e Cohn, expõe considerações acerca da tutela da saúde mental pelo Ministério Público Federal, assim como os consequentes reflexos da atuação dessa instituição na indução de políticas públicas destinadas para a proteção dos indivíduos com transtornos mentais e na superação do modelo de tratamento denominado de hospitalocêntrico, existente anteriormente. No terceiro artigo, A mediação como mecanismo de tutela do direito da saúde (6), os seus autores, Andrade e Lamy, declaram que há um elevado e crescente número de ações judiciais relacionadas à saúde, fato que enseja, em algumas ocasiões, ineficiência do Poder Judiciário e, nesse cenário, é preciso buscar métodos alternativos de soluções de conflitos, tal como a mediação sanitária, que tem produzido resultados positivos em algumas experiências desenvolvidas no país.

No quarto artigo, os autores Massarelli Júnior e Almeida abordam os impactos da lei de liberdade econômica sobre as sociedades médicas limitadas e a EIRELI (7), investigando a responsabilidade do médico decorrente das diversas possibilidades de configuração da pessoa jurídica prestadora de serviços médicos, a partir da promulgação da Lei no 13.874/2019, denominada de Declaração de Direitos de Liberdade Econômica, que trouxe alterações em diversos dispositivos legais, assim como a existência de um possível conflito com as novas regras da sociedade limitada e as relativas à empresa individual de responsabilidade limitada. 
A terceira parte da obra em análise diz respeito ao direito da saúde e tutela trabalhista e encontra-se dividida em dois artigos. No primeiro, Gestão sustentável da jornada de trabalho no sistema bancário e seus impactos no direito à saúde (8), Oliveira e Pinto buscam avaliar a gestão estratégica e sustentável da jornada de trabalho no sistema bancário e seus impactos para o direito da saúde, ante as alterações decorrentes da reforma trabalhista.

No segundo artigo, Síndrome de burnout: assédio moral e causalidade (9), Carvalho procura demonstrar que há fatores no ambiente de trabalho que contribuem para 0 desenvolvimento da referida síndrome, mas, para que seja possível responsabilizar o empregador, é necessária a comprovação da existência do nexo de causalidade entre o quadro clínico e fatores estressores do ambiente laboral.

A quarta parte da obra trata do direito da saúde e meio ambiente e divide-se em três artigos. No primeiro, Poluição atmosférica e saúde física e mental humana (10), Roldan e Lamy buscam explicitar as respostas para importantes indagações a respeito do direito à saúde física e mental e meio ambiente saudável e equilibrado como direitos humanos e fundamentais (10). No segundo artigo, Responsabilidade socioambiental das instituições financeiras no financiamento para aquisição de ônibus movidos a combustíveis fósseis, o foco de Senger e Lamy é mostrar a possibilidade de construção do entendimento de que uma instituição que financia a aquisição de meios de transporte em massa movidos a combustíveis fósseis pode ser responsabilizada, no âmbito socioambiental, por danos causados ao meio ambiente e à saúde da população urbana (11).

No terceiro capítulo, A degradação dos manguezais e os reflexos na saúde pública (12), o objetivo de Batista é tratar da ocupação irregular de manguezais como um reflexo de fatores como desemprego e endividamento, quando todos têm direito ao meio ambiente ecologicamente equilibrado, ao mesmo tempo em que essa degradação resulta das necessidades de uma comunidade carente, que não tem acesso ao mínimo existencial.

A quinta parte do livro é composta por 5 artigos sobre o tema direito da saúde e políticas públicas. Movimentos diaspóricos e saúde: o caso das grávidas venezuelanas no Brasil, de autoria de Silva, Toledo e Cabral, aponta as consequências geradas na saúde dos venezuelanos, principalmente quanto à ginecologia-obstetrícia e seus reflexos na realidade brasileira. Com o colapso do sistema de saúde da Venezuela, muitos migram para o Brasil, especialmente para Roraima, para receberem tratamentos de saúde, de modo que o Brasil tem atendido todos os casos de parturientes venezuelanas, assim como tem enviado 
esforços para contribuir na reposição de medicamentos e outros materiais da área médica e fornecer um atendimento igualitário (13).

O segundo artigo, Perspectivas do rastreamento mamográfico na prevenção secundária do câncer de mama, de Rubin e Lafasse (14) identifica as políticas públicas referentes à prevenção secundária ao câncer de mama no Brasil, analisando e avaliando a eficácia e a segurança do rastreamento mamográfico, ao qual muitas mulheres precisam se submeter como prevenção. Concluem que, para que os programas de rastreamento de câncer sejam eficazes em uma população, é precisa testar um grande número de mulheres saudáveis, que muitas vezes são mal informadas pelos governos e sobrediagnosticadas, submetidas a procedimentos invasivos e dolorosos, tratadas com terapias prejudiciais à saúde.

No terceiro capítulo, Os prejuízos sanitário da política industrial farmacêutica no Brasil (15), Costa analisa alguns prejuízos percebidos pela comunidade científica, originados da venda de medicamentos em embalagens indivisíveis. Tal fato ocasiona que o consumidor adquira mais medicamentos do que o necessário ou prescrito, sendo urgente a dispensação prudente. No quarto artigo, Depressão em homens e a necessidade de criação de programas específicos de prevenção ao suicídio para o gênero masculino, os autores Felipe, Costa e Almeida fundamentam a necessidade da criação de programas de prevenção específicos para o gênero masculino, dadas as suas várias ocupações na sociedade (16).

No último artigo, Avaliação da demanda de atendimentos emergenciais no prontosocorro da cidade de Cubatão e o direito constitucional à saúde, Gonzalez Cação, Santana Cação e Pinto (17) versam sobre a procura aos serviços de urgência e emergência pelos usuários do SUS, quando grande parte das queixas pode ser solucionada na rede de atenção básica, o que resulta no aumento da demanda do pronto-socorro, prejudicando a qualidade do atendimento.

A sexta e última parte da obra, trata do direito da saúde e o SUS e divide-se em três artigos. O primeiro, de autoria de Kozyreff, intitulado A remuneração do SUS e o impacto nas entidades filantrópicas prestadoras de serviço público de saúde (18), retrata o impacto que a Constituição de 1988 teve na estrutura da saúde no Brasil e entidades sem fins lucrativos - a latere do Estado - como prestadoras de serviço de saúde, anteriormente mantidas com poucos recursos provenientes da sociedade civil.

No segundo artigo, Ressarcimento ao Sistema Único de Saúde pelas operadoras de saúde e a improbidade administrativa (19) Zagarino pesquisa a existência ou não de 
controles nas redes de saúde nos municípios, que possibilite a conferência quanto ao cumprimento dos valores ressarcidos ao Fundo Nacional de Saúde pelos planos, e posteriormente repassados aos municípios.

Por fim, no último capítulo da obra, Dever de incorporação de medicamentos para doenças raras: o caso SPINRAZA (20), de autoria de Santos e Akaoui, o escopo é discutir a incorporação de medicamentos raros ao sistema de saúde por meio do Spinraza® (2), único tratamento recomendado e disponível no mundo para atrofia muscular espinhal (AME).

O que se pode depreender da presente obra é a confirmação da complexidade do direito à saúde, razão pela qual a leitura se faz indispensável. O Prof. Dr. Marcelo Lamy organiza temas atuais, trazendo-os de forma amadurecida, não oferecendo ao leitor repostas prontas, mas permitindo análises contundentes capazes de moldar possíveis soluções para problemas públicos e sociais do direito à saúde.

\section{Referências}

1. Fontes SC. Mandados de criminalização e proteção à saúde. São Paulo, SP: Matrioska Editora; 2020. Capítulo 1.1; p. 21-54. In: Lamy M (org). Temas avançados de direito da saúde [livro eletrônico]: tutelas jurídicas da saúde. São Paulo: Matrioska Editora; 2020. 328 p.

2. Gouveia WC, Souza LP. Mandado de criminalização do tráfico ilícito de entorpecentes: o caso das drogas sintéticas. São Paulo, SP: Matrioska Editora; 2020. Capítulo 1.2; p. 55-79. In: Lamy M (org). Temas avançados de direito da saúde [livro eletrônico]: tutelas jurídicas da saúde. São Paulo: Matrioska Editora; 2020. 328 p.

3. Felício EVM, Lamy M. Saúde e doenças no cárcere: fatores de produção e negligência estatal. São Paulo, SP: Matrioska Editora; 2020. Capítulo 1.3; p. 80-101. In: Lamy M (org). Temas avançados de direito da saúde [livro eletrônico]: tutelas jurídicas da saúde. São Paulo: Matrioska Editora; 2020. 328 p.

4. Bastos AT. Deficiências da perícia nas alienações parentais. São Paulo, SP: Matrioska Editora; 2020. Capítulo 2.1; p. 103-117. In: Lamy M (org). Temas avançados de direito da saúde [livro eletrônico]: tutelas jurídicas da saúde. São Paulo: Matrioska Editora; 2020. 328 p.

5. Silva CM, Cohn A. O Ministério Público Federal e a tutela do direito à saúde mental. São Paulo, SP: Matrioska Editora; 2020. Capítulo 2.2; p. 118-134. In: Lamy M (org). Temas avançados de direito da saúde [livro eletrônico]: tutelas jurídicas da saúde. São Paulo: Matrioska Editora; 2020. 328 p.

6. Andrade TCOR, Lamy M. A mediação como mecanismo de tutela do direito da saúde. São Paulo, SP: Matrioska Editora; 2020. Capítulo 2.3; p. 135-148. In: Lamy M (org). Temas 
avançados de direito da saúde [livro eletrônico]: tutelas jurídicas da saúde. São Paulo: Matrioska Editora; 2020. 328 p.

7. Massarelli Júnior JC, Almeida VSF. Impactos da Lei de Liberdade econômica sobre as sociedades médicas Ltda. e a EIRELI. São Paulo, SP: Matrioska Editora; 2020. Capítulo 2.4; p.149-165. In: Lamy M (org). Temas avançados de direito da saúde [livro eletrônico]: tutelas jurídicas da saúde. São Paulo: Matrioska Editora; 2020. 328 p.

8. Oliveira RB, Pinto RMF. Gestão sustentável da jornada de trabalho no sistema bancário e seus impactos no direito à saúde. São Paulo, SP: Matrioska Editora; 2020. Capítulo 3.1; p. 167-181. In: Lamy M (org). Temas avançados de direito da saúde [livro eletrônico]: tutelas jurídicas da saúde. São Paulo: Matrioska Editora; 2020. 328 p.

9. Carvalho EH. Síndrome de burnout: assédio moral e causalidade. São Paulo, SP: Matrioska Editora; 2020. Capítulo 3.2; p. 182-190. In: Lamy M (org). Temas avançados de direito da saúde [livro eletrônico]: tutelas jurídicas da saúde. São Paulo: Matrioska Editora; 2020. 328 p.

10. Roldam MR, Lamy M. Poluição atmosférica e saúde física e mental humana. São Paulo, SP: Matrioska Editora; 2020. Capítulo 4.1; p. 191-205. In: Lamy M (org). Temas avançados de direito da saúde [livro eletrônico]: tutelas jurídicas da saúde. São Paulo: Matrioska Editora; 2020. 328 p.

11. Senger OLC, Lamy M. Responsabilidade socioambiental das instituições financeiras no financiamento para aquisição de ônibus movidos a combustíveis fósseis. São Paulo, SP: Matrioska Editora; 2020. Capítulo 4.2; p. 206-223. In: Lamy M (org). Temas avançados de direito da saúde [livro eletrônico]: tutelas jurídicas da saúde. São Paulo: Matrioska Editora; 2020. 328 p.

12. Batista IM. A degradação dos manguezais e os reflexos na saúde pública. São Paulo, SP: Matrioska Editora; 2020. Capítulo 4.3; p. 223-237. In: Lamy M (org). Temas avançados de direito da saúde [livro eletrônico]: tutelas jurídicas da saúde. São Paulo: Matrioska Editora; 2020. 328 p.

13. Silva JCL, Toledo ACV, Cabral LFP. Movimentos diaspóricos e saúde: o caso das gravidas venezuelanas no Brasil. São Paulo, SP: Matrioska Editora; 2020; p. 240-256. In: Lamy M (org). Temas avançados de direito da saúde [livro eletrônico]: tutelas jurídicas da saúde. São Paulo: Matrioska Editora; 2020. 328 p.

14. Rubin, $B$, Lafasse R. Perspectivas do rastreamento mamográfico na prevenção secundária do câncer de mama. São Paulo, SP: Matrioska Editora; 2020; p. 258-295. In: Lamy M (org). Temas avançados de direito da saúde [livro eletrônico]: tutelas jurídicas da saúde. São Paulo: Matrioska Editora; 2020. 328 p.

15. Costa BBF. Os prejuíxos sanitários da política industrial farmacêutica no Brasil. São Paulo, SP: Matrioska Editora; 2020; p. 296-309. In: Lamy M (org). Temas avançados de direito da saúde [livro eletrônico]: tutelas jurídicas da saúde. São Paulo: Matrioska Editora; 2020. 328 p. 
16. Felipe MG, Costa YVC, Almeida VSF. Depressão em homens e a necessidade de criação de programas específicos de prevenção ao suicídio para o gênero masculino. São Paulo, SP: Matrioska Editora; 2020; p. 309-325. In: Lamy M (org). Temas avançados de direito da saúde [livro eletrônico]: tutelas jurídicas da saúde. São Paulo: Matrioska Editora; 2020. 328 p.

17. Cação EG, Cação AMSS, Pinto RMF. Avaliação da demanda de atendimentos emergenciais no pronto-socorro da cidade de Cubatão e o direito constitucional à saúde. São Paulo, SP: Matrioska Editora; 2020; p. 326-338. In: Lamy M (org). Temas avançados de direito da saúde [livro eletrônico]: tutelas jurídicas da saúde. São Paulo: Matrioska Editora; 2020. 328 p.

18. Kozyreff AM. A remuneração do SUS e o impacto nas entidades filantrópicas prestadoras de serviço público de saúde. São Paulo, SP: Matrioska Editora; 2020; p. 340356. In: Lamy M (org). Temas avançados de direito da saúde [livro eletrônico]: tutelas jurídicas da saúde. São Paulo: Matrioska Editora; 2020. 328 p.

19. Zarino Júnior S. Ressarcimento ao Sistema Único de Saúde pelas operadoras de saúde e a improbidade administrativa. São Paulo, SP: Matrioska Editora, 2020; p. 358-368. In: Lamy M (org). Temas avançados de direito da saúde [livro eletrônico]: tutelas jurídicas da saúde. São Paulo: Matrioska Editora; 2020. 328 p.

20. Santos AF, Akaoui FRV. Dever de incorporação de medicamentos para doenças raras: o caso SPIRANZA. São Paulo: Matrioska Editora; 2020; p. 369-380. In: Lamy M (org). Temas avançados de direito da saúde [livro eletrônico]: tutelas jurídicas da saúde. São Paulo: Matrioska Editora; 2020. 328 p.

\section{Colaboradores}

Todos os autores contribuíram com a concepção, elaboração, redação, revisão e aprovação da resenha.

\section{Como citar esta resenha:}

Ramos EMB, Costa LLS, Almeida NMO. Temas avançados de Direito da Saúde: tutelas jurídicas da saúde. Cadernos Ibero-Americanos de Direito Sanitário. 2020 out./dez.; 9(4): 198-204.

https://doi.org/10.17566/ciads.v9i4.750 